\title{
KUALITAS PRODUK DAN KUALITAS PELAYANAN DIPENGARUHI OLEH KEPUTUSAN PEMBELIAN PADA PT TRITANU HUBS INDONESIA
}

\author{
Nani dan Ade Ulfa \\ Program Studi Manajemen, Universitas Pamulang \\ Email: dosen01704@unpam.ac.id, ade.ulfah17@gmail.com
}

\begin{abstract}
ABSTRAK
Penelitian ini bertujuan untuk mengetahui pengaruh kualitas produk dan kualitas pelayanan terhadap keputusan pembelian pada PT. Tritanu Hubs Indonesia. Metode yang digunakan dalam penelitian ini adalah metode kuantitatif pendekatan deskriptif dengan menggunakan teknik pengambilan sampel yaitu purposive sampling dan jumlah sampel sebanyak 100 orang pelanggan PT Tritanu Hubs Indonesia. Untuk menguji data menggunakan analisa regresi linier berganda.Hasil dari analisis serta pembahasan menunjukan bahwa : (1)keputusan pembelian dipengaruhi oleh kualitas produk yang positif, (2)keputusan pembelian dipengaruhi kualitas pelayanan yang positif (3) keputusan pembelian dipengaruhi oleh kualitas produk dan kualitas pelayanan secara simultan.
\end{abstract}

Kata Kunci: Kualitas Produk, Kualitas Pelayanan, Keputusan Pembelian

\begin{abstract}
The research is to find out how purchasing decisions are influenced by product quality and service quality at PT. Tritanu Hubs Indonesia. The method used in this research is a quantitative method with a descriptive approach using a sampling technique that is purposive sampling and the total sample of 100 customers of PT Tritanu Hubs. The analytical method used is multiple linear regression. The results of the analysis and discussion show that: (1) positive product quality affects the purchasing decisions, quality positive service influences the purchase decision (3) product quality and service quality together influence the purchasing decision.
\end{abstract}

\section{Keywords: Product Quality,Service Quality,Purchasing Decision}

\section{PENDAHULUAN}

\section{A. Latar Belakang}

Perkembangan di bidang perekonomian selama ini telah banyak membawa akibat yang cukup pesat dalam dunia usaha, sehubungan dengan itu banyak perusahaan baru berdiri dan kembalinya perusahaan yang di revitalisas, maka berakibat timbulnya persaingan yang ketat diantara perusahaan-perusahaan tersebut. Baik itu persaingan antar perusahaan sejenis maupun perusahaan yang tidak sejenis. Untuk mengantisipasi hal ini tentunya perusahaan harus memiliki strategi yang tepat agar tetap mampu bersaing dengan perusahaan pesaing lainnya dan tetap dapat meningkatkan penjualan. Dalam hal ini salah satu strategi perusahaan yang dijalankan yaitu dengan terus berinovasi dalam upaya meningkatkan kualitas produknya.

Setiap organisasi atau perusahaan tentunya akan memperhatikan mutu produknya, supaya produk yang dihasilkan dapat bersaing dipasar. Kualitas produk berdasarkan pendapat Kotler (2012:283) adalah kemampuan 
sebuah produk dalam memperagakan fungsinya, hal ini termasuk keseluruhan durabilitas, reliabilitas, ketepatan, kemudahan pengoperasian dan reparasi produk juga atribut produk lainnya. Bentuk produk harus meliputi ukuran serta struktur fisik produk. Fitur meliputi aspek-aspek keistimewaan, karakteristik serta ragam keuntungan yang diintegrasikan atau dibawa didalam suatu produk terpapar kepada konsumen atau pelanggan. Termasuk didalamnya kesan kualitas, keunggulan merk, serta totalitas mutu dan gaya atau penampilan produk serta kesan konsumen terhadap produk. Produk menjadi instrument penting untuk mencapai kesuksesan dan kemakmuran pada perusahaan modern. Perkembangan teknologi, peningkatan persaingan global, serta kebutuhan dan keinginan pasar mengharuskan perusahaan melakukan pengembangan produk terus menerus dan hal ini merupakan salah satu cara sebuah perusahaan untuk meningkatkan kualitas pelayanannya.

Kualitas pelayanan adalah tingkat keunggulan yang diharapkan dan pengendalian atas tingkat keunggulan tersebut untuk memenuhi keinginan pelanggan menurut Tjiptono (2012:153). Apabila kualitas dikelola dengan tepat, maka berkontribusi positif terhadap terwujudnya kepuasan pelangan. Kualitas pelayanan yang baik juga memberikan nilai plus berupa motivasi khusus bagi para pelanggan untuk menjalin ikatan saling menguntungkan dalam jangka panjang dengan perusahaan. Dalam menilai pentingnya kualitas pelayanan suatu perusahaan harus mengetahui sejauh mana pelayanan itu dapat menciptakan tingkat kepuasan semaksimal mungkin bagi pelanggan. Mengenai kualitas pelayanan yang optimal dimana semakin tinggi antara harapan dengan kualitas pelayanan maka akan menciptakan nilai kepuasan yang maksimal.
Apabila dalam suatu perusahaan kualitas produk dan kualitas pelayanan yang diberikan masih kurang, hal ini berakibat terhadap keputusan pembelian dimana keputusan pembelian tidak terlepas dari bagaimana konsumen melalui beberapa tahap yaitu mengetahui masalah yang dihadapi sampai dengan terjadinya transaksi pembelian konsumen.

Menurut Kotler dan Keller (2012:195) salah satu bagian dalam perilaku konsumen adalah keputusan pembelian. Dalam melakukan keputusan pembelian ada beberapa tahap yang harus dilakukan oileh konsumen dimana tahap-tahap tersebut akan menghasilkan

keputusan dalam membeli atau tidaknya suatu produk. Apabila konsumen membeli suatu produk dan mereka merasa puas akan produk tersebut tentunya mereka akan melakukan pembelian ulang dan sebaliknya mereka akan beralih ke produk atau merk lain jika konsumen merasa tidak puas dengan produk yang mereka beli. Begitu pula dengan dengan yang dilakukan oleh PT Tritanu Hubs Indonesia tentunya berupaya terus memperbaiki kualitasnya baik dari segi produk maupun pelayanannya.

PT Tritanu Hubs Indonesia merupakan perusahaan asing swasta yang didirikan pada tanggal 22 maret 2005 yang masih berdiri sampai saat ini dengan moto nya "Quality Service Value" berhasil menempatkan posisi nya di pasaran Indonesia.. PT Tritanu Hubs Indonesia adalah organisasi dinamis dengan pengalaman lebih dari 25 tahun di industri ritel yang menyediakan solusi One-Stop untuk penyediaan sistem Rak/Gondola, Trolley Belanja, dan Display pendinginan (AHT). Customer yang dimiliki oleh PT Tritanu Hubs Indonesia antara lain Hero Supermarket, Giant, Carrefour, Transmart, Hypermart, Foodmart, Farmers Market, Ranch 


\begin{tabular}{ccccccc}
\hline No. & $\begin{array}{l}\text { Keluhan } \\
\text { Konsumen }\end{array}$ & 2014 & 2015 & 2016 & 2017 & 2018 \\
\hline 1 & $\begin{array}{l}\text { Gondola } \\
\text { cat nya } \\
\text { mudah } \\
\text { terkelupas }\end{array}$ & 14 & 23 & 19 & 35 & 54 \\
\hline $\begin{array}{l}\text { Trolley } \\
\text { roda nya } \\
\text { mudah } \\
\text { rusak }\end{array}$ & 21 & 17 & 40 & 25 & 36 \\
\hline Alah
\end{tabular}

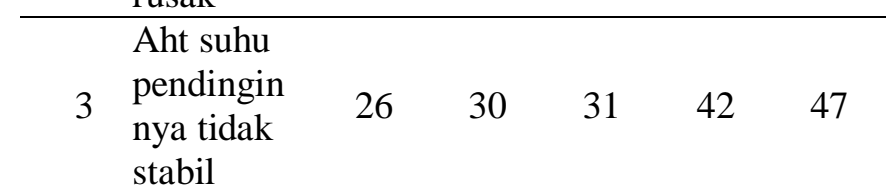

Market, The Foodhall, Guardian, Boston, Ministop, Lulu Supermarket dan lainnya. Untuk lebih mengetahui bagaimana kondisi penjualan PT Tritanu Hubs Indonesia yang lebih jelas tertera pada tabel 1 sebagai berikut.

\section{Tabel 1}

Data Penjualan

Sumber: PT.Tritanu Hubs Indonesia,2019

Berdasarkan data penjualan dari tabel 1 tersebut dapat dilihat bahwa penjualan produk PT Tritanu Hubs Indonesia mengalami fluktuatif dari tahun 2014 ke tahun 2018. Hal ini di duga karena banyak bermunculan kompetitor baru dengan produk yang lebih bervariatif dan mempunyai tingkat kualitas produk tinggi sehingga otomatis berpengaruh terhadap PT Tritanu Hubs Indonesia untuk itu selain kualitas produk juga hal yang harus diperhatikan PT Tritanu Hubs Indonesia yaitu kualitas pelayannya dan untuk mengetahui bagaimana kualitas pelayanan PT Tritanu Hubs Indonesia tertera pada tabel 2 dibawah sebagai berikut.

Tabel 2

Data Keluhan Pelanggan lain:

\section{Sumber: PT.Tritanu Hubs \\ Indonesia,2019}

Berdasarkan data tabel 2 diatas dapat dilihat bahwa tingkat keluhan pelanggan mengalami kenaikan lima tahun terakhir, ini menandakan masih kurangnya kualitas pelayanan yang diberikan PT Tritanu Hubs Indonesia kepada pelanggan, hal ini tentunya akan berdampak tidak baik terhadap volume penjualan produk PT Tritanu Hubs Indonesia.

\section{B. Rumusan Masalah}

Berdasarkan latar belakang penelitian, maka peneliti dapat merumuskan beberapa masalah antara

a) Bagaimana keputusan pembelian dipengaruhi oleh kualitas produk pada PT Tritanu Hubs Indonesia.

b) Bagaimana keputusan pembelian dipengaruhi oleh kualitas pelayanan pada PT

\begin{tabular}{|c|c|c|c|}
\hline Tahun & Gondola & Trolley & AHT \\
\hline 2014 & $\begin{array}{l}\text { Rp. } \\
23.910 .114 .273\end{array}$ & $\begin{array}{l}\text { Rp. } \\
7.887 .477 .703\end{array}$ & $\begin{array}{l}\text { Rp. } \\
5.066 .892 .829\end{array}$ \\
\hline 2015 & $\begin{array}{l}\text { Rp. } \\
9.584 .338 .238 \\
\end{array}$ & $\begin{array}{l}\text { Rp. } \\
2.485 .802 .804\end{array}$ & $\begin{array}{l}\text { Rp. } \\
\text { 9.899.929.286 }\end{array}$ \\
\hline 2016 & $\begin{array}{l}\text { Rp. } \\
14.695 .904 .477\end{array}$ & $\begin{array}{l}\text { Rp. } \\
1.915 .184 .250\end{array}$ & $\begin{array}{l}\text { Rp. } \\
32.246 .812 .850\end{array}$ \\
\hline 2017 & $\begin{array}{l}\text { Rp. } \\
20.297 .032 .730\end{array}$ & $\begin{array}{l}\text { Rp. } \\
22.005 .107 .986\end{array}$ & $\begin{array}{l}\text { Rp. } \\
44.682 .254 .128\end{array}$ \\
\hline 2018 & $\begin{array}{l}\text { Rp. } \\
12.487 .775 .209\end{array}$ & $\begin{array}{l}\text { Rp. } \\
243.395 .600\end{array}$ & $\begin{array}{l}\text { Rp. } \\
1.727 .106 .300\end{array}$ \\
\hline c) & $\begin{array}{l}\text { Tritanu Hubs In } \\
\text { Bagaimana kep } \\
\text { pembelian diper } \\
\text { kualitas produk } \\
\text { pelayanan pada } \\
\text { Hubs Indonesia }\end{array}$ & $\begin{array}{l}\text { lonesia . } \\
\text { tusan } \\
\text { garuhi oleh } \\
\text { dan kualitas } \\
\text { PT Tritanu }\end{array}$ & \\
\hline
\end{tabular}

\section{METODE PENELITIAN}

Metode penelitian yang digunakan adalah metode kuantitatif sedangkan berdasarkan tingkat eksplanasi yang 
digunakan dalam penelitian ini adalah secara deskriptif, karena memiliki tujuan untuk menyajikan gambaran secara terstruktur, faktual dan akurat mengenai fakta-fakta serta hubungan antar variable yang akan diteliti. Adapun dengan menggunakan pendekatan kuantitatif yaitu pendekatan yang memerlukan bantuan perhitungan ilmu statistic. Metode pengumpulan data yang digunakan adalah metode survei yang mengambil satu popluasi dan menggunakan kuesioner sebagai alat pengumpulan data primer. Dalam penelitian ini populasinya adalah pelanggan tetap PT.Tritanu Hubs Indonesia sebanyak 100 orang dan kemudian seluruhnya dijadikan sampel penelitian dengan menggunakan teknik purposive sampling. Untuk mengolah dan menganalisa data yang digunakan dalam penelitian ini yaitu menggunakan teknik uji validitas dan realibilitas,uji asumsi klasik yang terdiri dari uji normalitas ,uji multikolinearitas dan uji homokedastisitas,analisis regresi berganda dan teknik pengujian hipotesa yang terdiri dari uji parsial(uji t),uji signifikan simultan(uji f),koefisien determinasi(R2). Data diproses dengan menggunakan SPSS ver.24.0 untuk windows.

\section{HASIL DAN PEMBAHASAN}

Berdasarkan hasil pengujian validitas dan realibilitas, diketahui bahwa semua variable yang diuji bersifat valid dan reliable.Setelah selesai uji validitas dan realibilitas data kemudian dianalisis menggunakan uji asumsi klasik terhadap model regresi yang terdiri dari uji normalitas, uji multikolinearitas dan uji heterokedastisitas. Berdasarkan ketiga uji asumsi klasik tersebut,diketahui model regresi dapat digunakan karena telah sesuai dengan persyaratan yaitu:1)residual terdistribusi secara normal, 2)tidak terdapatnya gejala multikolinearitas, dan 3) tidak terjadi homokedastisitas.

\section{Uji Regresi Linier Berganda}

Uji regresi linier berganda ini dimaksudkan untuk mengetahui besaran pengaruh anatara dua variable yaitu variable $X$ ( kualitas pelayanan) dan variable Y (keputusan pembelian) hasil pengujiannya dapat dilihat dalam tabel dibawah ini.

Tabel 3

Pengolahan Uji Regresi Sederhana

\section{Sumber: Olah Data SPSS Ver.24.0}

Dari hasil persamaan regresi linier berganda tersebut dengan persamaan $\mathrm{Y}=18,769+0,279 \mathrm{X} 1+\mathbf{0 , 2 3 7 X}$, hal ini dapat di asumsikan yaitu :

a) Jumlah nilai konstanta 18,769 disebutkan apabila nilai variabel kualitas produk serta kualitas pelayanan nihil $=0$, ini artinya keputusan pembelian adalah sejumlah 18,769 .

b) Untuk variable kualitas produk koefisien regresi sebesar 0,279, memiliki makna jika terjadinya peningkatan jumlah satu poin untuk variable kualitas produk tentunya akan menambah keputusan pembelian 0,279. 
c) Dalam variable kualitas pelayanan koefisien regresinya 0,237 , memiliki makna jika terjadi peningkatan jumlahsatu poin untuk variable kualitas pelayanan, tentunya hal ini akan menambah keputusan pembelian sebesar 0,237 .

\section{Pengujian Hipotesis}

Adapun hasil pengujian hipotesis pertama menunjukan bahwa terdapat pengaruh yang positif dan signifikan antara kualitas produk terhadap keputusan pembelian. Hal ini diketahui dari hasil pengujian yang menunjukan nilai $t$ hitung $>$ ttabel atau $(5,515>$ 1,984).

Sedangkan hasil pengolahan hipotesa kedua menunjukan bahwa terdapat pengaruh yang positif dan signifikan antara kualitas produk terhadap keputusan pembelian. Hal ini diketahui dari hasil pengujian yang menunjukan nilai thitung> ttabel atau (4,991 > 1,984).

Terakhir hasil olah uji f menunjukan hasil yang positif dan signifikan secara bersamaan antara variable kualitas produk dengan keputusan pembelian. Hal ini diketahui dari hasil pengujian menunjukan bahwa Fhitung > Ftabel $(21,25>3,090)$.

\section{KESIMPULAN DAN SARAN}

\begin{tabular}{|c|c|c|c|c|c|}
\hline & & effic & nts $^{\mathrm{a}}$ & & \\
\hline Model & $\begin{array}{r}\text { Uns } \\
\mathrm{di} \\
\mathrm{Coe} \\
\mathrm{r}\end{array}$ & $\begin{array}{l}\text { ndar } \\
\text { ed } \\
\text { icie } \\
\text { Std }\end{array}$ & $\begin{array}{c}\text { Standa } \\
\text { rdized } \\
\text { Coeffi } \\
\text { cients }\end{array}$ & $\mathrm{t}$ & Sig \\
\hline & B & $\begin{array}{c}\text { Err } \\
\text { or }\end{array}$ & Beta & & \\
\hline $\begin{array}{ll} & \text { (Const } \\
\text { ant) }\end{array}$ & $\begin{array}{r}18.7 \\
69\end{array}$ & $\begin{array}{r}2.9 \\
33\end{array}$ & & $\begin{array}{r}6.3 \\
98\end{array}$ & 0 \\
\hline $\begin{array}{l}\text { Kualit } \\
\text { as } \\
\text { Produ } \\
\text { k (X1) }\end{array}$ & $\begin{array}{r}0.27 \\
9\end{array}$ & $\begin{array}{r}0.0 \\
74\end{array}$ & 0.357 & $\begin{array}{r}3.7 \\
66\end{array}$ & 0 \\
\hline $\begin{array}{l}\text { Kualit } \\
\text { as } \\
\text { Pelaya } \\
\text { nan } \\
\text { (X2) }\end{array}$ & $\begin{array}{r}0.23 \\
7\end{array}$ & $\begin{array}{r}0.0 \\
77\end{array}$ & 0.291 & $\begin{array}{r}3.0 \\
7\end{array}$ & $\begin{array}{r}0.0 \\
03\end{array}$ \\
\hline
\end{tabular}

a. Dependent Variable: Keputusan

\section{Kesimpulan}

1. Penelitian ini membuktikan adanya pengaruh positif dan signifikan antara kualitas produk terhadap keputusan pembelian pada PT Tritanu Hubs Indonesia.

2. Penelitian ini membuktikan adanya pengaruh positif dan signifikan antara kualitas pelayanan terhadap keputusan pembelian pada PT Tritanu Hubs Indonesia.

3. Penelitian ini membuktikan adanya pengaruh positif dan signifikan antara kualitas produk dan kualitas pelayanan secara simultan terhadap keputusan pembelian pada PT Tritanu Hubs Indonesia.

\section{Saran}

1. PT.Tritanu Hubs Indonesia harus tetap menjaga kualitas produknya dalam hal ini bahan material yang baik dari produkproduk yang telah dimilikinya selama ini terutama dalam bentuk produk, dengan cara menciptakan inovasi-inovasi baru agar pelanggan tertarik dengan produk yang dihasilkan dari perusahaan sehingga dapat menarik pelanggan untuk membeli produk dari PT Tritanu Hub's Indonesia.

2. PT Tritanu Hubs Indonesia harus meningkatkan kualitas pelayanannya terutama bagaimana menjaga komunikasi yang baik dengan pelanggan, cepat tanggap dalam menghadapi keluhan dan segera mengatasi masalah mereka, selain itu pula perlu ditingkatkan lagi misalnya dengan memberikan promo-promo yang menarik baik potongan harga ataupun dalam bentuk hadiahhadiah kepada pelanggannya dimana jika pelanggan puas dengan pelayanan perusahaan 


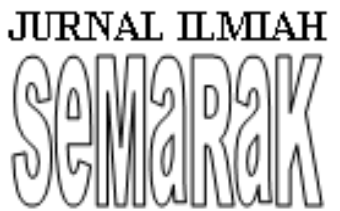

otomatis mereka akan tetap setia untuk membeli produk PT Tritanu Hubs Indonesia.

3. Untuk kedepannya perlu adanya penelitian lebih lanjut lagi selain tentang kualitas produk dan kualitas pelayanan supaya semakin menambah khasanah keilmuan bidang Manajemen Pemasaran umumnya dan khususnya PT Tritanu Hubs Indonesia.

\section{DAFTAR PUSTAKA}

Dharmmesta, Basu Swastha, Handoko, T. Hani. 2013. Manajemen Pemasaran Analisis Prilaku Konsumen. Edisi Pertama. BPFE, Yogyakarta.

Ghozali, Imam, 2011,Aplikasi Analisis Multivariate dengan Program SPSS, Edisi Kelima, Badan Penerbit Undip, Semarang.

Keller dan Amstrong,2012, Prinsipprinsip Pemasaran, Edisi Kedua Belas, Jilid Satu, Erlangga, Jakarta.

Kotler, Philip, Keller, Kevin Lane. 2013. Manajemen Pemasaran. Edisi 13,Erlangga. Jakarta.

Kotler, Philip,2012, Manajemen Pemasaran, Edisi Keempat belas, PT. Indeks, Jakarta.

Qurbani, D., \& Pasaribu, V. L. D. (2019). PENGARUH BRAND IMAGE DAN BRAND TRUST TERHADAP BRAND LOYALTY NASABAH PRUDENTIAL SYARIAH PADA PT. FUTURISTIK ARTHA GEMILANG (Studi kasus di kantor cabang agensi Prudential Syariah PT. Futuristik
Artha Gemilang Jakarta Selatan). Jurnal Pemasaran Kompetitif, 2(3), 121-135.

Pasaribu, V. L. D., \& Prayoga, M. Y. S. (2019). PENGARUH KUALITAS PRODUK BAJU BATIK HEM TERHADAP KEPUASAN PELANGGAN PADA HOME INDUSTRI BATIK SAHARA INDAH. Jurnal Pemasaran Kompetitif, 2(2), 77-83.

Pasaribu, V. L. D., \& Jaenanto, J. (2020, January). PENGARUH KUALITAS PELAYANAN TERHADAP TINGKAT KEPUASAN PENYEWA RUANG KANTOR DI PT ISMAWA TRIMITRA GEDUNG GRAHA ISKANDARSYAH PERIODE 2018 JAKARTA SELATAN. In PROCEEDINGS (Vol. 1, No. 1).

PASARIBU, V. L. D. (2017). ANALISIS PENGARUH PROMOSI, KUALITAS PRODUK DAN DESAIN KEMASAN TERHADAP PERSEPSI MEREK YANG BERDAMPAK KEPADA KEPUTUSAN PEMBELIAN HAND AND BODY LOTION MEREK VASELINE (Studi Kasus TIP TOP Ciputat, Tangerang Selatan). INOVASI, 4(2). 